\title{
HISTORICAL CONDITIONS IN DESIGNING PRE-SCHOOL CENTERS, ON THE EXAMPLE OF GERMANY AND UKRAINE
}

\author{
Denis Saenko \\ assistant, architect \\ Author's Orcid number: 0000-0002-8120-3381 \\ Odessa State Academy of Civil Engineering and Architecture (OSACEA), Odessa, Ukraine \\ State Higher Education Establishment \\ Department of Architecture of buildings and structures
}

\begin{abstract}
The article considers the peculiarities of the architectural organization of children's preschool institutions in European countries on the example of Germany and Ukraine in the 20th century. The study examines examples of architectural design of preschool institutions in the dense urban development of foreign cities, which are of particular importance for further solving of domestic problems of preschool institutions location in Ukrainian urban settlements. The considered projects demonstrate individual design decisions of kindergartens with revealing of regional features and local traditions of the countries which at the same time correspond to modern educational programs of these countries and reflect the advanced world tendencies in designing of children's preschool institutions.
\end{abstract}

Key words: preschool institutions, integrated-attached type, kindergarten, educational institutions, architecture. 


\section{INTRODUCTION}

Functioning children's preschool institutions in Ukraine today are mostly represented by typical detached buildings built by the industrial methods of construction of the second half of the twentieth century. A significant period of time, which distances us from the last wave of mass construction of preschools in Ukrainian cities, became the basis for the formation of new conditions and, as a consequence, changes in architectural, demographic, social, economic, energy, aesthetic etc. character. Within the framework of global processes of urbanization, the urban building system has been compacted and in all large domestic cities we can observe the lack of free territories for the construction of service facilities, including those intended for preschool function. The prevailing market relations, capitalization and the desire to create the maximum number of living meters on the minimum land area have led to the emergence of new areas with dense high-rise housing, mostly inhabited by young families, and the issue of servicing these areas is still open. Realizing that the previous project approach to solving the architectural organization of preschool education is no longer able to meet modern conditions and needs, it is necessary to turn to world experience, rethink it and identify positive and negative features for their further integration in our country.

\section{MATERIALS AND METHODS}

The article presents research on the history of the establishment of preschool institutions and analysis (Kovalski 1988, Kovalska, 2010) of the historical formation of the architectural environment and typology of Ukraine. The active phase of development of the urban network of children's preschool institutions (next - CPI) and the formation of their typological types abroad began in the early 20s of the twentieth century (simultaneously with the beginning of these processes in Ukraine as part of the USSR) (Kovalski 1988). The need for mass distribution of preschools in civilized countries was caused by various circumstances: the severe consequences of the First World War, a number of revolutions in Europe, economic and political crises, the need for labor, etc., which together led to the urgent need to provide CPI in short terms and with low construction costs. Thus, on the outlined basis, the world experience of designing CPI with various regional architectural and planning principles and methods of organization and formation of the architectural environment of preschool education in Europe, Asia, America and others took place. At the same time analysis of the historical formation of the architectural environment and typology of CPI buildings of the Soviet period of Ukraine allows us to identify several stages of its development. These stages are associated with socio-political and cultural changes in our country, which occurred as a result of the Soviet government and the creation of a new national system of education, based on which the development of typology of CPI buildings in domestic practice.

The first period (1918-1922). Kindergartens and nurseries in the first period were moved to mansions and adapted buildings. The need for this kind of public service has been growing rapidly every year. This was especially felt in large Ukrainian cities, such as Kyiv, Odessa, Kharkiv, and others. Along with the active deployment of the construction program, the first buildings of children's preschools began to appear, which were designed to perform this function. These were mostly small facilities, designed for 25-50 people, usually did not have their own territory and were built into or attached to existing buildings.

The second period (1923-1940). It is characterized by the beginning and active transition to mass housing construction throughout our country. During this period, a methodology for the construction of children's institutions was developed, the first educational programs were formed. An important step was the introduction of the first regulations on the design of CPI. Design and construction of children's preschool institutions in this period took place on individual architectural projects. In 40$50 \%$ of cases, children's preschools were designed and placed on the first floors of residential and public buildings, which can be considered as the first steps towards the development of integratedattached type of preschools. In 1928, official norms were developed for the design of children's preschool institutions with the definition of the area of the kindergarten. One of the typical projects of a nursery for 50 places (by architect C. B. Knyazev, 1938) confirms great attention to the architecture of children's preschool institutions. The original frontal composition of the main facade of the 
building is based on the combination and alternation of various patterns of the planes of wooden elements (Fig. 1). In the conditions of transition to mass housing construction in Ukraine the methodology of construction of children's institutions was developed, educational programs were made and the first norms of designing of CPI were entered. Construction of children's preschool institutions was carried out on individual projects. $40-50 \%$ of children's institutions were designed built into the first floors of residential and public buildings.
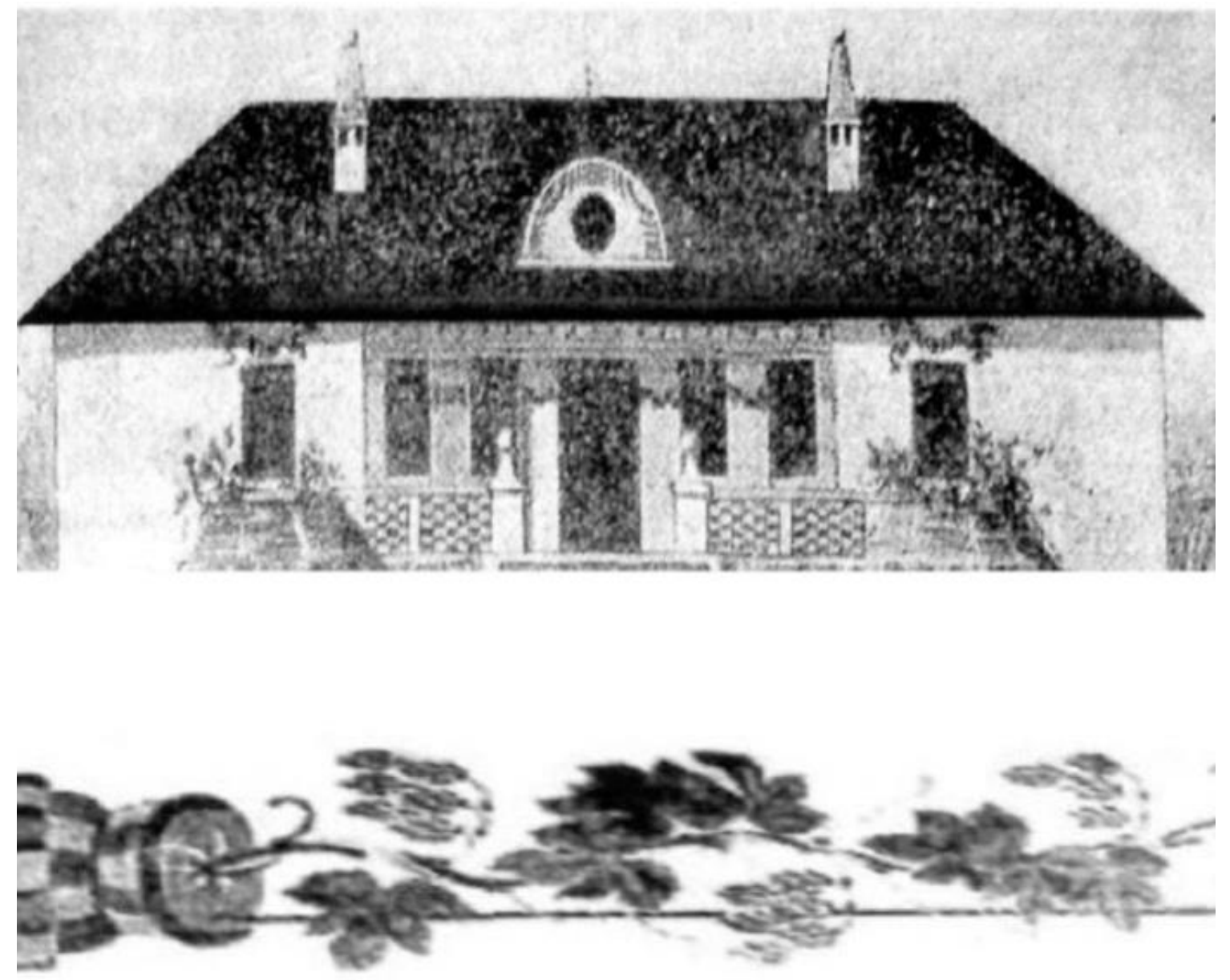

Fig. 1. Project of a kindergarten for 50 places by architect Knyazev S.V. with a fragment of painting on the facade Soure: Kowalski, 1938

The third period (1941-1950). This period of Ukraine's development is distinguished by difficult conditions of post-war time, a sharp decrease in the total fund of children's educational institutions. The main design and building efforts of the first post-war years were aimed at restoration of the existing housing fund. Stationing of CPI had place in practically any building, most often combined with buildings of schools, district administrations, hydraulics. 
The fourth period (1951-1960). It is characterized by the active expansion of urban settlements with the construction of large residential areas. Construction and design of CPI has become widespread. It should be noted that this historical stage of development and design of CPI in Ukraine was a turning point - the aesthetics of the three-dimensional framework of the building of the children's institution began to be based on identifying and emphasizing the functional structure of the building.

The fifth period (1961-1970). The spread of mass construction of residential areas in this period of development of Ukraine led to a decrease in construction costs, the use of simplified structural schemes, standardization of architectural elements, active use of standard design, which in turn led to simplification of three-dimensional composite schemes of buildings. In 1961-1970, the main percentage of CPIs built were separately located buildings. The design of CPI of integrated-attached type began to be exceptional and received the status of "experimental construction" (Kovalska, 2010).

The sixth period (1971-1991). The development and further increase in the total volume of housing construction led to an improvement in the quality of construction, an increase in the number of experimental architectural and construction projects with the introduction of integrated-attached type CPI in large cities of Ukraine. In 1979, in the departments of Central Scientific Research and Design Institute of Residential and Public Buildings and Kiev Zonal Research and Design Institute for Experimental Design, which were engaged in the design of educational buildings, a pilot project of a transformed institution of integrated-attached type was developed for 14 groups, with increased capacity up to 350 seats, designed for construction in new cities and large residential areas. Unfortunately, despite the significant advantages of using lightweight structures (prefabricated, with the possibility of further transformation), which opened wide opportunities for flexible planning and external transformation, such experimental proposals in the design of CPI buildings of integrated-attached type remained unrealized (Kovalska, 2010).

Beginning with the collapse of the USSR to the present day, we can distinguish the seventh period (1991 - nowadays). In Ukraine, the 1990s are characterized by a crisis in political, economic and financial, demographic, social, educational and others. areas, which had a negative impact on the entire architectural and construction sector.

Thus, the current stage of development and design of children's preschool institutions in Ukraine is characterized by a general trend of individual project approach related to determining the dynamics of demand for places in children's institutions and taking into account the forecast solutions in the organization of CPI, especially integrated-attached type of institutions. Recently, there has also been a trend of qualitative leap in the design, construction, organization and operation of educational buildings, including preschool education, which in turn is due to the need to differentiate the types of CPI by capacity, location and architectural planning organization with different types of buildings depending on the population density and specific urban conditions. Unfortunately, the current network of CPI in Ukraine responds insufficiently and slowly to the changing social, demographic and economic requirements of the population of our country, as well as reforms in education, including in its preschool sector.

The next logical step of this article is analyzing progressive and innovative foreign experience in design, construction and operation of childcare institutions, with a focus on use of integrated-attached type architectural organization forms of which will be the next study title. Further systematization of the received data, identifying the best, innovative and effective foreign project decisions in the following sections of the thesis will be useful in developing new-made proposals for design of the children's preschool institutions of integrated-attached type in modern Ukraine.

\section{PRESCHOOL EDUCATION IN GERMANY}

Preschool education in Germany is considered a model of the education system for the whole European Union. Preschool education is carried out in kindergartens, preschool classrooms and school kindergartens. Due to the fact that in the early 90 s of the twentieth century. Preschool institutions were attended by about $75 \%$ of children, the task was taken to provide places exclusively to all 
children until 2001. From 1957 in Germany acts law about free visit of kindergartens, of which 20\% owned by state, and $80 \%$ - owned by the church community, trade unions, the German Red Cross, service for youth and other charitable organizations. In the center of educational work of kindergarten is social education with the purpose of raising a conscious and communicative personality. Children learn, first of all, by mean of playing. Some of them attend kindergarten only in the first half of the day, and after lunch they are again in their family. Others stay in the kindergarten all day until the early evening.

It should be noted the diversity of types of preschool institutions of Germany: kindergartens with a full or incomplete day, for 3-6 years aged children; one-group preschool institutions (mostly for senior preschoolers); school groups (for five-year-old children); preparatory classes of primary school (they raise and teach five-year-old children until reaching school age); all-day boarding school for healthy children aged 3 to 6 years, as well as boarding houses for children with health and developmental disabilities; kindergartens of free and open type.

The most common type of free kindergarten - Steiner kindergartens and Montessori kindergartens. The work of these institutions is based on the situation-oriented concept of preschool education, which is characterized by: open planning, in which children participate; learning based on real life connections; unity of play and learning; different age organization of life and activity; public relations; cooperation between parents and preschool. The peculiarities of the preschool system of education in Germany include the presence of so-called maternal centers, in which children together with their mothers are engaged in interesting and useful activities. Note that mothers have the opportunity to communicate with each other and with specialists in pedagogy and psychology.

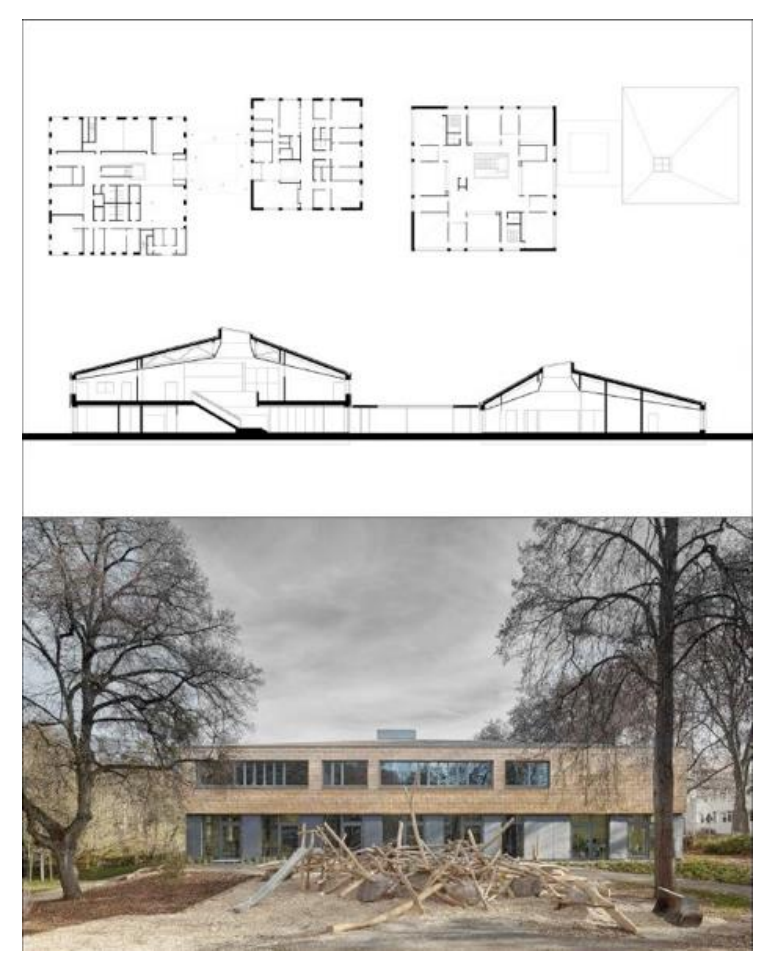

Fig. 2. Primary school and a children's center in Tübingen. Germany, (Se) arch Architekten, 2016. Source: (Children's Center-Primary, 2016)

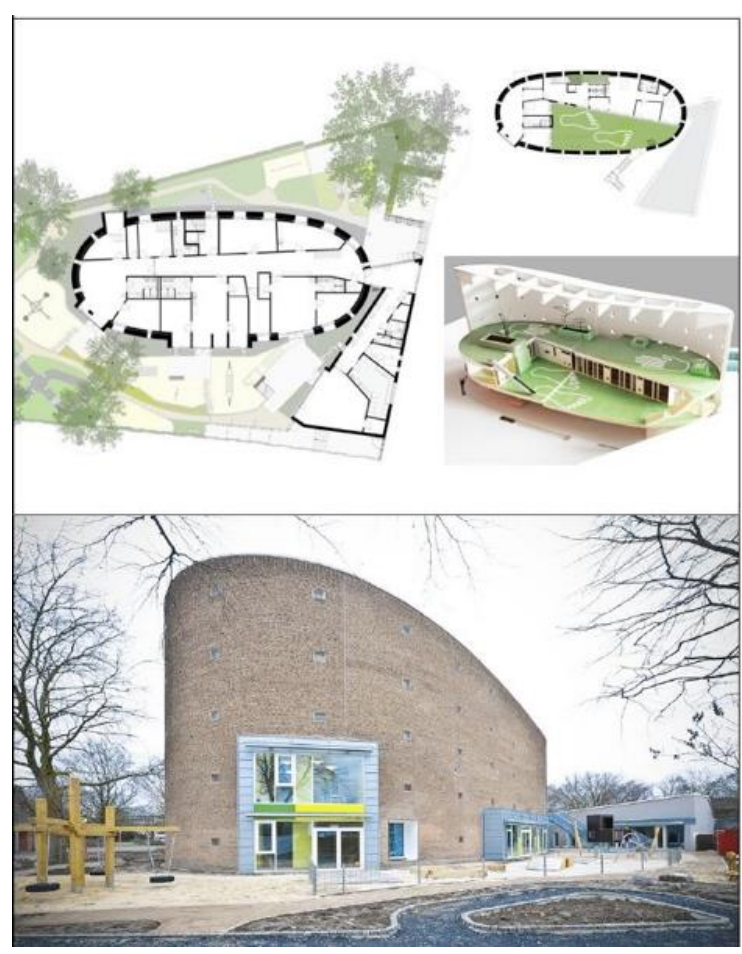

Fig. 3. Kindergarten in Münster, Germany, BOLLES + WILSON, 2013. Source: (Kindergarten in Münster, 2020) 
An example of modern preschool education in Germany is the project of the Stuttgart studio (Se) arch Architekten, which combines a primary school and a children's center in Tübingen (Fig.2) a located in a wooded area on the banks of the Neckar River, the intercultural training center includes a children's playroom and primary school classrooms. The architectural plan combined two separate volumes of the children's educational building on both sides around the courtyard. The one-story children's center and two-story elementary school have square plans and pyramidal roofs with truncated tops, which give the building a faceted look.

The entrance to the children's center begins with a multifunctional space with clothes storage space, which is illuminated from above by a square glass lantern. The office is located on one side of the entrance space, while the three main rooms, located opposite the rear of the building, face the play area, located among the trees. The entrance to the primary school leads to the open ground floor, which contains a multifunctional space, a cafe and a library. All areas are designed to offer free space for meetings and interaction, as well as to get more comfortable audiences located on the top floor (Children's Center-Primary School, Tübingen, Germany, 2016).

Another interesting example of the organization of a preschool institution is the project of a kindergarten from Bolles + Wilson, opened in 2013 in Münster (Germany) (Fig. 3.). The peculiarity of the object is the fact that it is a project-illustration of the renovation of the church premises for a new function of a preschool institution. The kindergarten is designed for three group rooms on the ground floor and two groups on the second floor of the building. Successfully converted church walls and roof helped to create an unusual open play environment for children's development (Kindergarten in Münster, Germany, 2013).

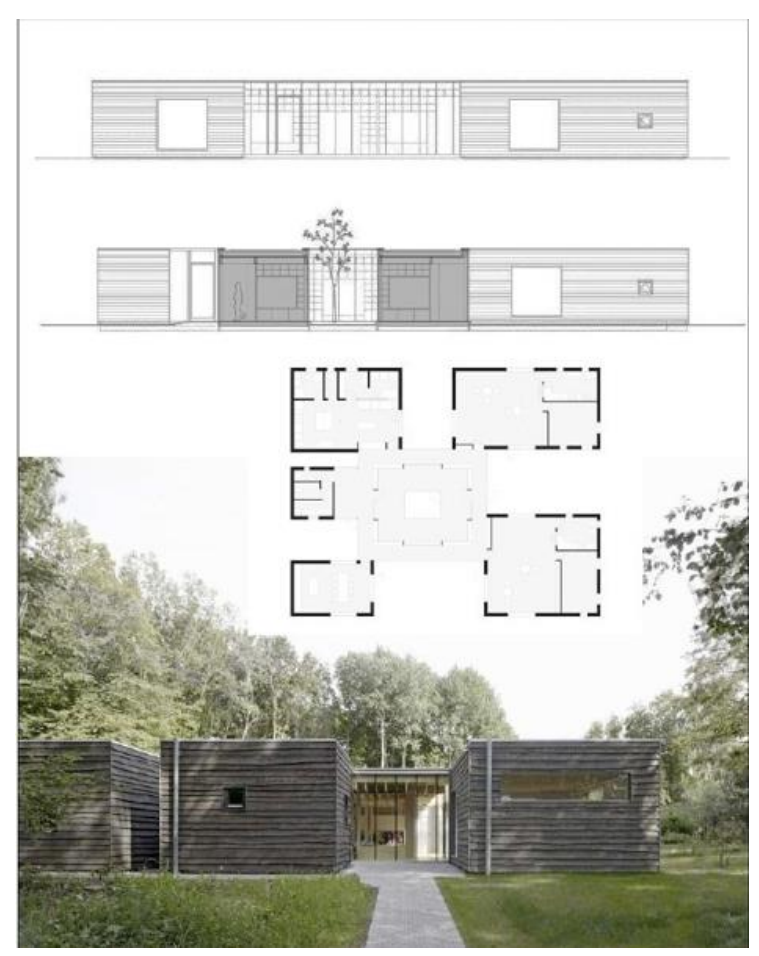

Fig. 4. Kinderkreisel preschool in Hamburg, Germany, Kraus Schönberg, 2015. Source: (Schönberg K)

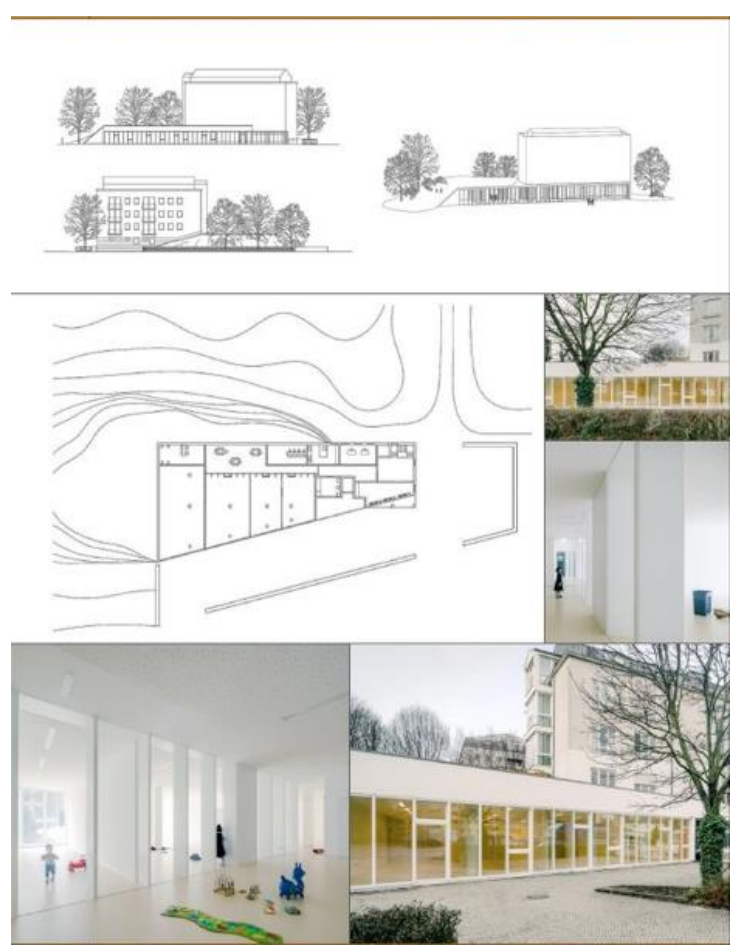

Fig. 5. Kindergarten KitaF in Berlin, Germany, Jan Rösler Architekten, 2016. Source: (Rösler J., 2016) 
The Kinderkreisel preschool project, designed by architect Kraus Schönberg and built in 2015 in Hamburg, Germany, occupies a large area where children can play and learn in the natural environment, among the trees (Fig. 4). Neat attitude to nature is an important part of the pedagogical concept of preschool. Classes, kitchen and utility rooms are grouped around a common space for active play. In the center of the preschool is the atrium, through which daylight enters the interior (Kinderkreisel Preschool, Hamburg, Germany, 2016).

A very interesting example of a rational German approach to buildings, which eventually lose the need for their function - the renovation of the video library in the attached kindergarten KitaF with an area of $750 \mathrm{~m}^{2}$. The project was completed in 2016. by Jan Rösler Architekten BDA in Berlin (Germany) (Fig. 5). The one-storey existing building of the former video library in the plan has a polygonal shape and a significant area of facade glazing, thanks to which daylight lighting was the conceptual focus of the project. Through the new window system and the highest possible height of the room, the light penetrates deep into the room. (KitaF Preschool, Berlin, Germany, 2016).

In addition, maximum transparency is created between open and at the same time separate functional zones inside the premises of the preschool institution. Group rooms, the dining room, most of the corridors and some secondary rooms, such as the kitchen and the office, are optically connected by fixed glazing of the wall elements. Along the facade, all group rooms are united by a line of sight along the entire length of the building. In this way, the original feeling of a "spacious room" is preserved, and new additional fragments of walls and partitions only divide the space into functional zones.

\section{CONCLUSIONS}

So, summing up, we can say that each country has its own approach to shaping the architecture of preschool educational institutions, based primarily on cultural and regional characteristics, feelings of necessity and expediency, the progressiveness of the education system as a whole. Characteristic of foreign $\mathrm{CPI}$ is the use of recreational and communication areas for educational purposes. This project approach is based on the inclusion of places of rest and recreation in the area of educational and developmental games. With this purpose, there is a distribution of functional units and individual architectural and planning components of the $\mathrm{CPI}$, which to some extent have educational potential: construction of stairways with the possibility of placing additional seats (in the form of enlarged steps) in the recreation areas, holding literary circles, thematic meetings, reading stories and fairy tales for a small group of children; placement of bathrooms and washbasins in the entrance area (in the lobby) promotes the development of personal hygiene skills, habits of cleanliness and order of pets; the use of walls, partitions and hanging elements for play purposes (for jumping, climbing, building mazes, etc.) significantly expands the range of creating play potential of the architectural space of the preschool institution.

As a result of the analysis of the studied examples experience of formation of network of CPI the following progressive tendencies of designing are allocated: necessity of the organization of flexible system of service of the population by kindergartens and nurseries which is under the influence of a number of dynamic factors; intensification of the use of the territory of residential complexes due to the inclusion in the structure of the network of CPI buildings of the integrated-attached type, which have urban maneuverability and allow to individualize housing construction; the need to expand the nomenclature type of CPI buildings with the introduction of flexible and transformational architectural and planning structures of children's preschool institutions of the integrated-attached type; individual project approach, which takes into account regional features, urban context, natural and climatic conditions, progressive educational programs, etc.

The study of the current state of development of the CPI system in Ukraine revealed the following problems: the existing domestic principles and approaches to the formation of preschool education do not solve the problem of quantitative services for the population; there is no methodology for taking into account dynamic demographic fluctuations in the design of $\mathrm{CPI}$, as well as the corresponding models of transformation and flexibility of the premises of preschool institutions, depending on the content; the density of buildings and population in historical and high-rise areas of cities, in 
which there is an acute problem with the organization of remote sensing data, is not taken into account.

\section{BIBLIOGRAPHY}

Children's Center-Primary School, Tübingen, Germany. URL: https://www.dezeen.com/2016/12/12/shinglecladding-school-search-architekten-cobbled-courtyard-tubingen-germany, 2016 (access 2021-14-07).

Kindergarten in Münster, Germany. URL: https://www.e-architect.com/germany/kindergarten-muenster 2020, (access 2021-14-07).

Schönberg K. Kinderkreisel Preschool, Hamburg, Germany. URL: https://divisare.com/projects/319515-krausschonberg-hagen-stier-kinderkreisel (access 2021-14-07).

Rösler J. KitaF Preschool, Berlin, Germany 2016. URL: https://www.architonic.com/en/project/jan-rosler-architekten-kitaf/5103310 ((access 2021-14-07).

Kovalska G.L. Arkhitekturne proektuvannya navchal'nykh zakladiv: navch. posib. [Architectural design of educational institutions: textbook. way]. Kyiv: KNUBA, 2010.

Kowalski L.N. Arkhitektura uchebno-vospitatel'nykh zdaniy [The architecture of educational buildings]. Kyiv: Budivelnik, 1988.

The education system in Germany. URL: https://en.wikipedia.org/wiki/Education_in_Germany. (access 202114-07).

\section{AUTHOR'S NOTE}

Saenko Denis, Ph.D. student, assistant of the Department of Architecture of buildings and structures, Odessa State Academy of Civil Engineering and Architecture. The main area of research: history of preschool institutions.

Contct | Kontakt: densayenko@gmail.com 